\title{
CARDIAC TROPONINS FOLLOWING REPEATED ADMINISTRATION OF AN IRON CHELATOR - SALICYLALDEHYD ISONICOTINOYL HYDRAZONE (SIH) - IN RABBITS
}

\author{
Michaela Adamcová1, Martin Štěrba ${ }^{2}$, Ivona Klimtová3 ${ }^{3}$ Tomáš Šimůnek ${ }^{3}$, Radomír Hrdina ${ }^{3}$, \\ Vladimír Geršl $l^{2}$, Přemysl Poňka ${ }^{4}$
}

Charles University in Prague, Faculty of Medicine in Hradec Králové: Department of Physiology ${ }^{1}$, Department of Pharmacology2; Faculty of Pharmacy in Hradec Králové: Department of Pharmacology and Toxicology ${ }^{3}$; McGill University, Montréal, Québec: Department of Physiology and Medicine ${ }^{4}$

Summary: Both cardiac troponin T (cTnT) and cardiac troponin I (cTnI) are considered to be reliable biomarkers with sufficient sensitivity and specificity for cardiac injury in the majority of laboratory animals. The aim of our study was to compare the diagnostic performance of cTnT and cTnI in three groups of rabbits: 1) control (saline $1 \mathrm{ml} / \mathrm{kg}$ i.v.); 2) Salicylaldehyd Isonicotinoyl Hydrazone - SIH ( $50 \mathrm{mg} / \mathrm{kg}$, once weekly, i.p.; partially dissolved in 10 \% Cremophor solution); 3) $10 \%$ Cremophor solution in water $(2 \mathrm{ml} / \mathrm{kg}$ i.v. $)$. The drugs were given once a week, 10 administrations. The concentration of cTnT was measured using Elecsys Troponin T STAT Immunoassay (Roche). The concentration of cTnI was measured using AxSYM Troponin I (Abbott). The linear regression model was applied to see if there is a dependence between cTnT and cTnI. The coefficient of determination was not acceptable in all groups. The highest value of $\mathrm{R}^{2}$ was found in the control group $\left(\mathrm{R}^{2}=0.424\right)$. We may conclude that in rabbits meaningful dependence between cTnT and cTnI was not found. According to our long-term experiences cTnT seems to be more suitable cardiomarker in rabbits in comparison with cTnI where the data are characterized by the large scatter.

Key words: Salicylaldehyd Isonicotinoyl Hydrazone (SIH); Iron chelator; Troponin; Rabbit; Biochemical marker

\section{Introduction}

The results of our previous studies showed that cardiac troponin $\mathrm{T}$ may be a useful predictive marker of daunorubicin-induced cardiomyopathy in rabbits $(1,2)$. The aim of this paper was to compare the diagnostic performance of cardiac troponin I (cTnI) and cardiac troponin $\mathrm{T}(\mathrm{cTnT})$ following repeated administration of a new drug belonging to Fe-chelating agents - SIH (Salicylaldehyd Isonicotinoyl Hydrazone).

Iron chelators could be very useful in many pathological states resulting from both the iron-overload and the formation of free radicals. At present, deferrioxamine (DFO) is the only Fe chelator used in clinical practice. The newly developed, very promising tridentate Fe-chelating compounds brings to the Pyridoxal Isonicotinoyl Hydrazone $(\mathrm{PIH})$ class. In previous studies, the repeated i.p. administration of PIH or a PIH analogue - SIH (Salicylaldehyde Isonicotinoyl Hydrazone) in a dose $50 \mathrm{mg} / \mathrm{kg} /$ week did not induce marked signs of toxicity in rabbits $(3,7,12)$. Due to the very low water solubility (13), the SIH - as well as the
PIH - have to be partially dissolved in a $10 \%$ Cremophor solution (a polyoxyethylated castor oil) and administer intraperitoneally.

\section{Methods}

All experiments used in this study were approved by the Ethical Committee of the Charles University, Faculty of Medicine in Hradec Králové.

Medium size Chinchilla male rabbits of average weight $3 \mathrm{~kg}$ at the beginning of the experiment served as experimental animals. The study was carried out on three groups of animals:

- control - saline (Spofa, Czech Republic - $1 \mathrm{ml} / \mathrm{kg}$ i.v.), once a week, 10 administrations, $\mathrm{n}=10$

- SIH (P. Poňka, McGill University, Montreal, Canada $50 \mathrm{mg} / \mathrm{kg}$ i.p.) partially dissolved in a $10 \%$ Cremophor EL (Sigma-Aldrich, Czech Republic), once a week, 10 administration, $\mathrm{n}=8$

- 10 \% Cremophor EL solution (Sigma-Aldrich, Czech Republic $-2 \mathrm{ml} / \mathrm{kg}$ i.v.), once a week, 10 administrations, $\mathrm{n}=5$ 
The venipunctures for biochemical examination were performed in the selected time intervals during the whole experiment (before and $24 \mathrm{hrs}$ after the $1^{\text {st }}, 5^{\text {th }}, 8^{\text {th }}$, and $10^{\text {th }}$ administration).

The concentration of cTnT in heparinized plasma samples was measured using Elecsys Troponin T STAT Immunoassay (Roche) on the Elecsys 2010 immunoassay analyser (Roche). The concentration of cTnI in heparinized plasma samples was measured using AxSYM Troponin I (Abbott) on the analyser AxSYM (Abbott).

\section{Statistical analyses}

Statistical evaluation was performed with the SigmaStat software program (revision STAT 32 2.0, Jandel $\mathrm{GmbH}$, Erkrath, Germany).

\section{Results}

In the both control and Cremophor groups, the values of cTnT were very low (i.e. $<0.03 \mathrm{ng} / \mathrm{ml}$ ). The repeated i.p. administration of SIH caused no statistically significant increase of cTnT levels in comparison either with the initial values or with both the control and the Cremophor groups. This observation confirmed very low cardiotoxicity of SIH declared in previous studies. The data about cTnT and cTnI are summarized in Table 1 and 2.

Furthermore, we have studied relationship between cTnT (independent variable $x$ ) and cTnI (dependent variable $Y$ ) using linear regression in the form $Y=\alpha+\beta x+\varepsilon$. First, we have tested the hypothesis that $\beta=0$ which would mean that $Y$ is independent of $x$. We have found out that hypothesis of independence was accepted only in the group following repeated administration of SIH and Cremophor but not in the control group. Further, the strength of dependence was measured with the coefficient of determination $\mathrm{R}^{2} . \mathrm{R}^{2}$ was too small in all cases. The highest value of $\mathrm{R}^{2}$ was found in the control group $\left(\mathrm{R}^{2}=0.424\right)$. It means that such a model is not suitable for prediction. The data are shown in the following figures; statistical characteristics are given in Table 3.
Tab. 3: Simple linear regression of cTnI depending on cTnT.

\begin{tabular}{|l|c|c|c|}
\hline Group & $\boldsymbol{n}$ & $\begin{array}{c}\mathbf{H}_{\mathbf{0}}: \boldsymbol{\beta}=\mathbf{0} \\
\mathbf{p}-\text { value }\end{array}$ & $\mathbf{R}^{\mathbf{2}}$ \\
\hline Control & 76 & 0.000 & 0.424 \\
\hline SIH & 62 & 0.677 & 0.003 \\
\hline Cremophor & 38 & 0.579 & 0.009 \\
\hline
\end{tabular}

$\mathrm{H}_{0}: \beta=0-c T n T$ is independent of $c \operatorname{Tn} T ; \mathrm{R}^{2}$ - coefficient of determination

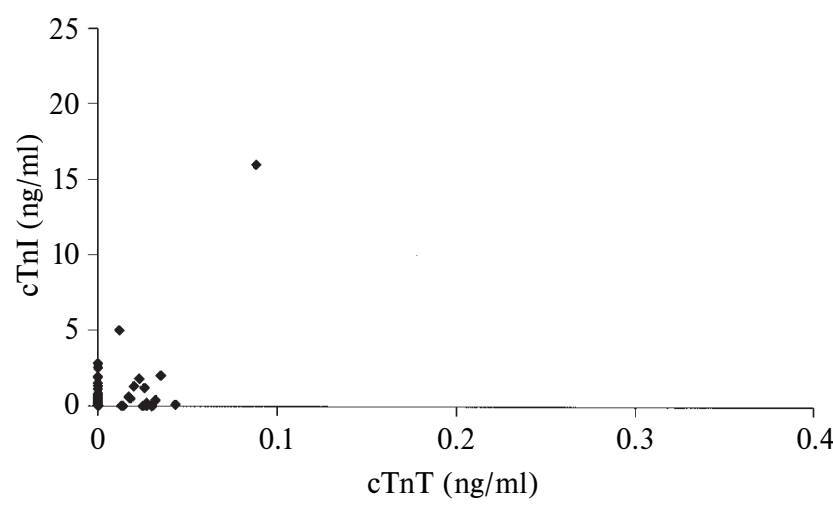

Fig. 1: Control group.

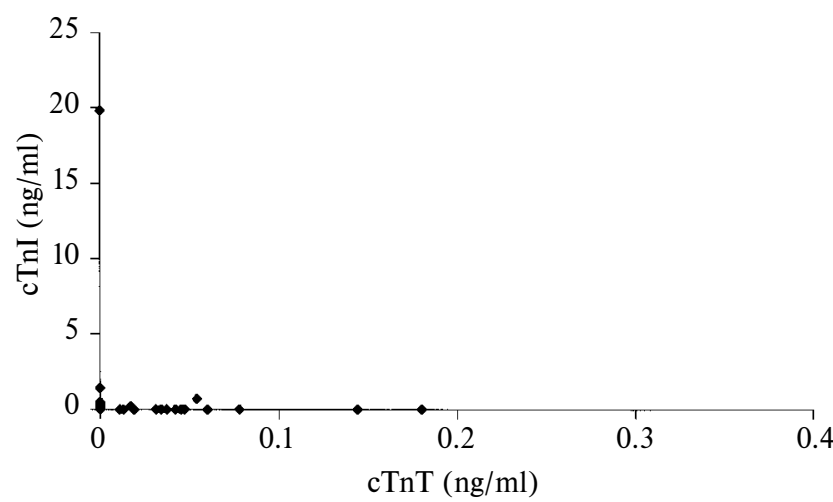

Fig. 2: Group following repeated administration of SIH.

Tab. 1: Cardiac troponin T (cTnT) levels (ng/ml) following SIH.

\begin{tabular}{|c|c|c|c|c|c|c|c|c|c|}
\hline Group & $n$ & \begin{tabular}{|l|} 
before $\mathbf{1}^{\text {st }}$ \\
administration
\end{tabular} & \begin{tabular}{|l|} 
after $\mathbf{1}^{\text {st }}$ \\
administration
\end{tabular} & \begin{tabular}{|l|} 
before $\mathbf{5}^{\text {th }}$ \\
administration
\end{tabular} & \begin{tabular}{|l|} 
after $\mathbf{5}^{\text {th }}$ \\
administration
\end{tabular} & \begin{tabular}{|l|} 
before $\mathbf{8}^{\text {th }}$ \\
administration
\end{tabular} & \begin{tabular}{|l|} 
after $\mathbf{8}^{\text {th }}$ \\
administration
\end{tabular} & \begin{tabular}{|l|} 
before $\mathbf{1 0}^{\text {th }}$ \\
administration
\end{tabular} & $\begin{array}{l}\text { after } \mathbf{1 0}^{\text {th }} \\
\text { administration }\end{array}$ \\
\hline Control & 10 & $0.003 \pm 0.003$ & $0.014 \pm 0.008$ & $0.000 \pm 0.000$ & $0.005 \pm 0.003$ & $0.000 \pm 0.000$ & $0.008 \pm 0.004$ & $0.000 \pm 0.000$ & \pm 0.005 \\
\hline $\mathrm{SIH}$ & 8 & 00 & 0 & 00 & 0. & 00 & 11 & 004 & 022 \\
\hline Cremophor & 5 & $0.000 \pm 0.000$ & $0.000 \pm 0.000$ & $0.000 \pm 0.000$ & $0.000 \pm 0.000$ & $0.000 \pm 0.000$ & $0.010 \pm 0.007$ & $0.000 \pm 0.000$ & $0.015 \pm 0.008$ \\
\hline
\end{tabular}

Tab. 2: Cardiac troponin I (cTnI) levels (ng/ml) following SIH.

\begin{tabular}{|c|c|c|c|c|c|c|c|c|c|}
\hline Group & $n$ & $\begin{array}{l}\text { before } \mathbf{1}^{\text {st }} \\
\text { administration }\end{array}$ & $\begin{array}{l}\text { after } \mathbf{1}^{\text {st }} \\
\text { administration }\end{array}$ & $\begin{array}{l}\text { before } \mathbf{5}^{\text {th }} \\
\text { administration }\end{array}$ & $\begin{array}{l}\text { after } \mathbf{5}^{\text {th }} \\
\text { administration }\end{array}$ & $\begin{array}{l}\text { before } \mathbf{8}^{\text {th }} \\
\text { administration }\end{array}$ & $\begin{array}{l}\text { after } \mathbf{8}^{\text {th }} \\
\text { administration }\end{array}$ & $\begin{array}{l}\text { before } \mathbf{1 0}^{\text {th }} \\
\text { administration }\end{array}$ & $\begin{array}{l}\text { after } \mathbf{1 0}^{\text {th }} \\
\text { administration }\end{array}$ \\
\hline Control & 10 & $0.578 \pm 0.271$ & $2.670 \pm 1.550$ & $0.270 \pm 0.127$ & $0.170 \pm 0.132$ & $0.510 \pm 0.285$ & $0.512 \pm 0.324$ & $0.356 \pm 0.203$ & $0.510 \pm 0.269$ \\
\hline SIH & 8 & $0.025 \pm 0.025$ & $0.088 \pm 0.058$ & $0.086 \pm 0.071$ & $0.000 \pm 0.000$ & $2.829 \pm 2.829$ & $0.287 \pm 0.181$ & $0.038 \pm 0.038$ & $0.000 \pm 0.000$ \\
\hline Cremophor & 5 & $0.000 \pm 0.000$ & $0.000 \pm 0.000$ & $0.000 \pm 0.000$ & $0.000 \pm 0.000$ & $0.060 \pm 0.060$ & $0.275 \pm 0.160$ & $0.325 \pm 0.325$ & $0.000 \pm 0.000$ \\
\hline
\end{tabular}




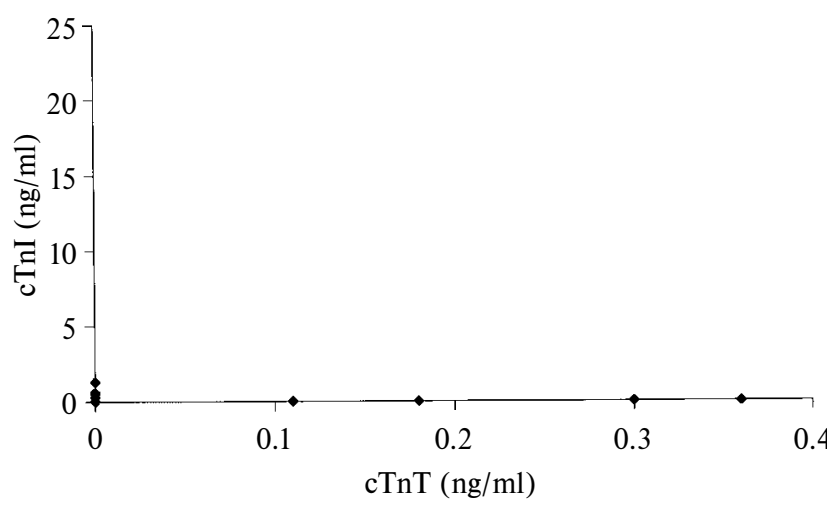

Fig. 3: Group following repeated administration of Cremophor.

\section{Discussion}

Troponin consisting of three subunits (TnT, TnC and TnI) belongs to the regulatory proteins involved in the regulation of muscle contraction in response to alterations in intracellular $\mathrm{Ca}^{2+}$ concentrations. Both subunits, i.e. cTnT and cTnI, are considered to be reliable biomarkers with sufficient sensitivity and specificity for cardiac injury in the majority of laboratory animals $(10,11)$. In our previous study (4) we measured serum concentration of both cardiomarkers in more than 100 samples obtained from rabbits under various conditions. A surprisingly strong dependence of cTnI on cTnT was found only in the control group. The group with repeated administration of daunorubicin and the second one with daunorubicin combined with dexrazoxane had the coefficients of determination too small to be considered acceptable. Similar results (i.e. no correlation between cTnT and cTnI) have been also reached in this study. Very low cTnT levels (i.e. $<0.03 \mathrm{ng} / \mathrm{ml}$ ) following repeated administration of SIH almost exclude possible cardiotoxic effect of SIH and are in an agreement with other followed-up parameters (12). On the other hand, the cTnI are widely scattered in all groups including the control group.

Better results with cTnT may be caused (except a little different characteristics, i.e. molecular weight, intracellular compartmentation etc.) by heterogenous nature and biochemical complexity of the serum forms of TnI and by differences of the epitope recognition using the various serum cTnI assays (5). Up to 20 -fold variation of serum cTnI mass determinations may be observed for a given sample when measured by different assay systems (8).

While only one commercial assay currently exists for cTnT determination using the monoclonal antibodies (Mab 7 and 7-11) against the central portion of the molecule, that is relatively stable and unaffected by the binding of TnT with other subunits, a number of cTnI assays are available recognizing different epitopes on the $\mathrm{N}$ - and C-termini of cardiac TnI. Four commonly used troponin I assays (Dade Behring Stratus, Beckman Coulter Access, Abbott
AxSYM, and Dade Behring Opus) recognize the intact cardiac troponin molecule, the Stratus, Opus, and AxSYM assays recognize the N-terminal portion of the molecule, and the Access assay recognizes the C-terminal portion of the molecule (8). Terminal portions of cTnI very often undergo oxidation and phosphorylation which can affect conformation of the molecule. Additionally, peripheral parts of cTnI are highly susceptible to proteolysis, and are often complexed with other troponin subunits that can also change the immunoreactivity of cTnI (5). While Katrukha et al. (6) reported that serum troponin I exists largely as a TnI-TnC binary complex with a small amount of free TnI present, Morjana (9) described that serum TnI exists predominantly as a ternary TnI-TnC-TnT complex. The extent of degradation may be related to the degree of myocardial damage.

To sum up, no meaningful dependence of cTnI on cTnT (with the exception of control group) has been found in rabbits. Although the choice of the best biochemical marker of myocardial damage does not seem to be simple and may differ from one species to another, further studies are needed because there is an increasing interest in the specific detection of myocardial damage in pre-clinical experiments (14). According to our long-term experiences cTnT seems to be more suitable cardiomarker in rabbits in comparison with cTnI.

\section{Acknowledgments}

The authors wish to thank Mrs. Ludmila Koželuhová for her technical assistance. This study was supported by a Grant GA CR 305/03/1511 and by Research Projects MSM 111500002.

\section{References}

1. Adamcová M, Geršl V, Hrdina R, Palička V, Mazurová Y. Contribution to prediction and pathogenesis of daunorubicin-induced cardiomyopathy in rabbits. Exp Clin Cardiol 1998;3(3):179-83.

2. Adamcová M, Geršl V, Hrdina R et al. Cardiac troponin T as a marker of myocardial damage caused by antineoplastic drugs in rabbits. J Cancer Res Clin Oncol 1999;125 (5):268-74.

3. Adamcová $\mathrm{M}$, Macháčková $\mathrm{J}$, Geršl $\mathrm{V}$ et al. Cardiac troponin $\mathrm{T}$ following repeated administration of pyridoxal isonicotinoyl hydrazone in rabbits. Phys Res 2002;51(5):443-8.

4. Adamcová $\mathrm{M}$, Geršl $\mathrm{V}$, Macháčková $\mathrm{J}$ et al. Troponins in experimental studies Acta Med (Hradec Králové) Suppl 2002;45(1):29-32.

5. Engliš M. Troponin T ( $\mathrm{cTnT}$ ) nebo troponin $\mathrm{I}(\mathrm{cTnI})$ : je to (ta správná) otázka? Labor Aktuell 1998;4:12-3.

6. Katrukha A, Bereznikova A, Filatov V et al. Degradation of cardiac troponin I: implication for reliable immunodetection. Clin Chem 1998;44:2433-40.

7. Klimtová I, Šimůnek T, Geršl V et al. Biochemical and haematological change following repeated pyridoxal isonicotinoyl hydrazone administration in rabbits. Biomarkers Environ 2001;4(Suppl 1):70-5.

8. Laurino JP. Troponin I: an update on clinical utility and metod standartization. An Clin Lab Science 2000;30(4): 412-21.

9. Morjana NA. Degradation of human cardiac troponin I after myocardial infarction. Biotechnol Appl Biochem 1998:28:105-11.

10. O'Brien PJ, Dameron GW, Beck ML, Brandt M. Differential reactivity of cardiac and skeletal muscle from various species in two generations of cardiac troponin immunoassays. Res Vet Sci 1998;65(2):135-7.

11. O’Brien PJ, Dameron GW, Beck ML et al. Cardiac troponin T is a sensitive, specific biomarker of cardiac injury in laboratory animals. Lab Anim Science 1997;47(5):486-95

12. Šimůnek T, Klimtová I, Hrdina R et al. The effects of repeated administration of pyridoxal isonicotinoyl hydrazone on cardiovascular system in rabbits. Biomarkers Environ 2001;4 (suppl 1):93-7. 
13. Sookvanichsilp N, Nakornchai S, Weerapradist W. Toxicological study of pyridoxal isonicotinoyl hydrazone: acute and subchronic toxicity. Drug Chem Toxicol 1991;14:395-403.

14. Wu AHB. Role of serum biochemical markers in clinical trials. In: Myocardial damage, Kasi JC and Holt DW (eds.) Developments in Cardiovascular Medicine. Kluwer Academic Publishers 1998; 205:189-98.

Submitted July 2003.

Accepted August 2003.

Doc. MUDr. Michaela Adamcová, Ph.D., Charles University in Prague, Faculty of Medicine in Hradec Králové, Department of Physiology,

Šimkova 870, 50038 Hradec Králové, Czech Republic. e-mail: adamcova@lfhk.cuni.cz 